\title{
EDITORIAL
}

\section{Neurosurgery in Italy: the past, the present, the future}

\author{
Luciano Mastronardi • Luigi Ferrante
}

Received: 8 December 2008 /Revised: 26 February 2009 /Accepted: 14 April 2009 / Published online: 23 June 2009

(C) Springer-Verlag 2009

Keywords Neurosurgery Italy $\cdot$ Trauma $\cdot$ Brain tumor . Microsurgery $\cdot$ Spine $\cdot$ Residency program $\cdot$ History

\section{Introduction}

The history of Italian neurosurgery probably started a very long time ago, about 5000 B.C. [1]. Anyway, we owe the most part of information to the scientific contributions of Professors B. Guidetti and R. Giuffrè [2, 5-7]. The aim of this short review is to report the practice of neurosurgery in Italy from the past to the present time, highlighting yesterday and today issues.

\section{The origins}

The origins of Italian neurosurgery are identified in the sixth millennium B.C. [1]. In Catignano, a prehistoric village near Pescara (central Italy), the skull of a mature woman with deep and extended remodeling of cranial vault was found. The lesions in cranial vault of this prehistoric woman were two large tunnel-shaped depressions with small holes completely crossing the braincase at their bottom: (1) on the top of interparietal suture and (2) near

L. Mastronardi $(\bowtie)$

Department of Neurosurgery, Sant'Andrea Hospital,

Via di Grottarossa 1035, 00189 Rome, Italy

e-mail: mastro@tin.it

\section{Ferrante}

Department of Neurosurgery,

Sant'Andrea Hospital, University of Roma "La Sapienza",

Via di Grottarossa 1035, 00189 Rome, Italy the center of left parietal bone [1]. Were the origins of these lesions artificial or the effects of a surgical procedure? Macroscopic, microscopic, and radiographic analyses showed close analogies with lesions characteristic of scalping. Scraping of cranial vault was done with a rough lancet, probably a stone knife-rounded. Concentric movements eroded and detached the periostium [1].

$\mathrm{X}$-rays showed a line of increased bone density in the left frontal bone: probably a healed and well cicatrized fracture. The possible diagnosis is head injury with multiple fractures of cranial vault. In this case, surgery seems to be related to the fractures rather than ritual reasons. The woman survived at least 1 year after treatment (in relation to the degree of bone reabsorption and new bone formation).

After a huge gap of "silence", in the Roman period, there are several witnesses of paleopathological cases of cranial trephination for removing inflected bone fragments produced by depressed fractures of the cranial vault. The Roman surgeon Galenus described this surgical technique in detail [6].

Bone drills were presumably driven in rotary motion by means of a thong in various configurations. Roman physicians used bone drills to excise diseased bone tissue from the skull and to remove foreign objects of considerable thickness (such as a weapon; Fig. 1).

\section{Middle Age}

During twelfth century, occasional reports of "brain surgery" (traumatic or surgical laceration of brain) are attributed to Carbondula da Vercelli, Rogerius Frugardi (surgeon of the Salerno school; Fig. 2), and Rolando da Parma (surgeon of the Bologna school) $[3,6]$. 


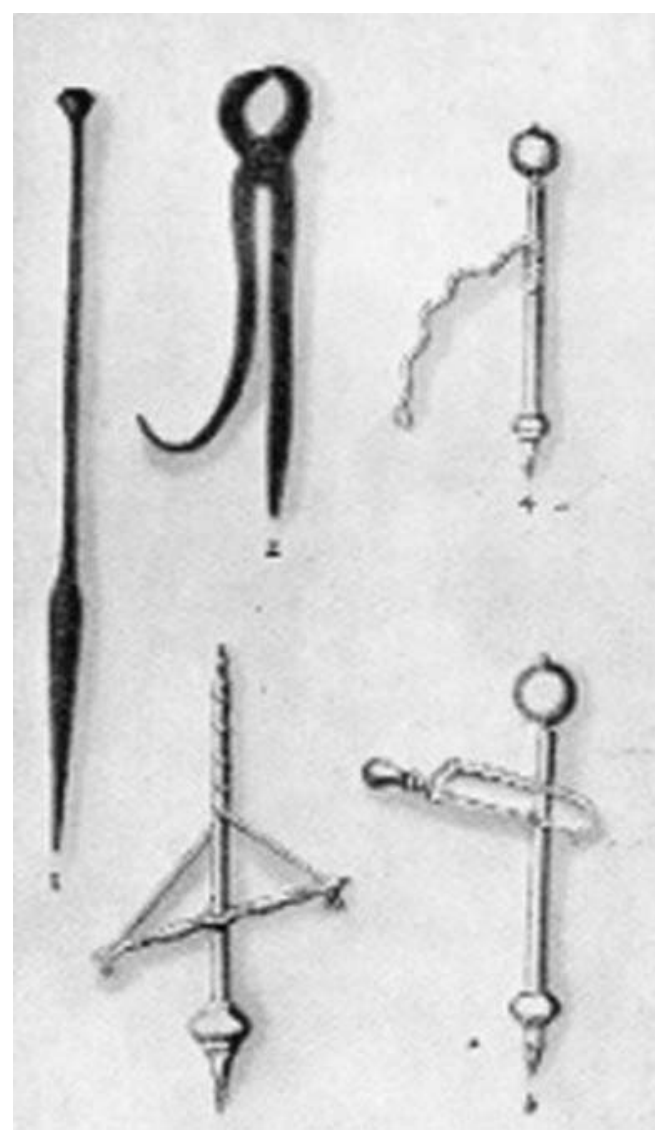

Fig. 1 Bone drills of the Roman period

In thirteenth century, Guglielmo of Saliceto (Piacenza) wrote the manuscript Surgery of nervous system (central and peripheral): from quacks and mystics to scientific basis: "...A surgical operation is not surgery but merely stems from it. Surgery is a boundless science demanding infinite knowledge. Those who operate without the necessary scientific knowledge may succeed by chance in a few operations. This does not alter the fact that they are unreasoning and ignorant men" [6].

In the same century, Guido Lanfranchi (Milan) created the first school of surgery in Italy. In his manuscript Chirurgia magna, he reported the cases of two soldiers who recovered after loss of tissue from the anterior part of the brain, presenting poor memories and dull wits. $\mathrm{He}$ concluded that "...the seat of thought is accessible to the surgeon's hand". Known Italian anatomists leaving in this century were Vesalius, Eustachio, and Falloppio [6].

\section{Sixteenth (Renaissance) and seventeenth (Inquisition) centuries}

After a gap of about 300 years, in the sixteenth century, Giovanni Vigo da Rapallo ("the Genoese") was the first to propose trephining in Italy in the manuscript Practica copiosa in Arte chirurgica ad filium Aloisium [6]. In the same period, Mariano Santo da Barletta in the Compendium in chirurgia utilissimum volentibus ipsam exercere observed that "...signs of broken cranial bone are vomiting, scotoma, giddiness, blindness and collapse ... at the time of the blow; in some cases apoplexy, stupor and fever ..." [6].

Giacomo Berengario da Carpi (Modena) in the Tractatus perutilis et completus de fractura cranei evaluated the timing of craniectomy in head injury: immediate operation in any case or operation only at the onset of symptoms? In this manuscript, he described various types of instruments and drills bits. He criticized medical men who, not having studied surgery, rashly want to try their hand at it for gain. They solved their ignorance with the help of surgeons of little account, with detriment of poor mankind: “...the blind leads the blind and both fall into the ditch" [6].

At the end of sixteenth century, Gabriele Ferrara wrote the Nuova selva di cirurgia divisa in tre parti, reporting his experience in the surgery of peripheral nerves. He firstly described suture of the stumps of a transected nerve: (1) immersion in decoction of red wine, rosemary, and roses, (2) gentle traction on the retracted stumps, (3) suture using a special needle, and (4) insulation of sutured segment with a mixture of oils [6].

During the seventeenth century, Cosimo Magari practiced as surgeon in Rome, Naples, Bologna, and later as professor in Ferrara. He reported important observations in the field of cranial traumatology: (1) head injuries without bone fractures can be associated to possible contusion of meninges and brain, (2) there are differences between depressed fractures with compressive effect and those

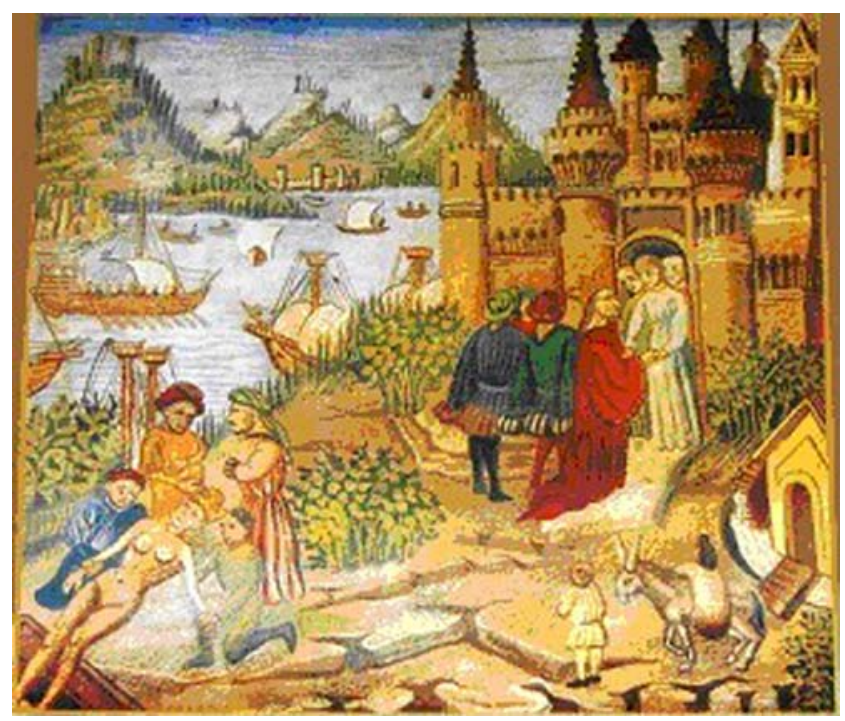

Fig. 2 Unknown: artistic paint resembling the brain surgery at the age of the School of Salerno 
without repercussions on the brain, and (3) reported topical remedies in severe head injuries [6]. In the same period, the surgeon Pietro Marchetti reported the advisability of cranial trephining in epilepsy and venereal headache in the manuscript Sylloge observationum medico-chirurgicorum rariarum [6].

\section{Eighteenth (Illuminism) and nineteenth (Modern Age) centuries}

In eighteenth century, Giovanni Ambrogio Bertrandi practiced as surgeon in Turin University. In the Anatomical and surgical works (manuscript of 14 volumes), he suggested when trephination of the skull could be performed systematically without abuse [6].

In the same period, the School of Surgery of Bologna began to be very famous with (1) Anton Maria Valsalvabig teacher of surgery, (2) Pietro Molinelli-upholder of cranial trephination, (3) Gaetano Sacconi wrote De non nullis cranii ossiumque fractures, and (4) Giovan Battista Morgagni-famous Italian surgeon and pupil of Valsalva studied and practiced the cranial trephination [6].

In the second half of eighteenth century, Francesco Biumi practiced as surgeon in Milan and reported the first case of bleeding intracranial aneurysm (a parasellar aneurysm of the carotid siphon) and correlated the clinical pattern with postmortem findings [6]. During the nineteenth century, the indications for neurosurgical treatment multiplicates in Italy and the various subspecialties into which neurosurgery was to divide began to delineate.

In the field of neurotraumatology, indications to trephine started to be based on clinical basis. In particular, A. VaccàBerlinghieri and A. Renzi, surgeons of the University of Pisa, observed that (1) the site of intracranial blood extravasation is not always in relation with external lesions, (2) the law of crossed hemiplegia is not applicable in every case, and (3) the temporal region is the zone of choice for trephination [6]. F. Rizzoli, from the University of Bologna, noted the importance of progressive, rather than immediate onset of signs of brain compression after a severe head injury and recognized the concept of "free interval" in extradural traumatic hematomas [6].

In the field of surgery of central nervous system tumors, during this century, several Italian surgeons started to sustain that intracranial tumors should be removed promptly and completely. A. Vacca Berlinghieri, in the Trattato di Chirurgia teorico pratico, and Z. Pecchioli (University of Siena) [5] suggested the surgical steps for the removal of "fungus" or "sarcoma" of the dura mater (meningioma): (1) craniectomy of bone flap with five to six burr holes, (2) removal of tumor with the dura mater from which it arose with a knife and tie the cut vessels, and (3) occlusion of meningeal artery at the edge of the bone, if it was damaged during resection [6].

During these years, Italian fundamental contributions to the knowledge of the neuroanatomy (and therefore of neurosurgery) were given from Giulio Casserio, who firstly discovered the anastomotic circulation (Poligon) at the base of the skull 37 years before Willis, and Luigi Rolando, who identified the sensory-motor sulcus [7] (Fig. 3).

In September 1885, the Sicilian surgeon Francesco Durante operated on in Rome a "fibrosarcoma" of the dura mater (meningioma) of the olfactory groove, may be the Italian operation most widely known abroad [4, 68]. The operation was presented at the surgical section of the International Medical Congress in Washington and published in the prestigious journal Lancet (1887) [4]. Some particular aspects regarding this case have to be stressed: (1) the operation was performed on the surgeon's own diagnosis based on clinical evidences (hyposmia, memory deficit, exophthalmos), (2) it was a challenging tumor of the skull base, (3) the excision was radical (over 11 years of good survival), and (4) a second operation for relapse was performed, with a survival of almost other 9 years $[4,6-8]$.

At the end of nineteenth century, the Italian obstetrician L. Gigli (1898) invented a twisted wire saw for cutting the symphysis pubis, widely used for neurosurgical purposes by applying a metal guide to protect dura mater. During the same year, D. Giordano devised a transnasal-frontoethmoidal approach to the pituitary gland (1898) [6].

In the last two decades of this century, an increasing number of operations for intracranial tumors were reported (Table 1). In the first years of this century, there were some Italian pioneers of neurosurgery and in the middle of the century, there were the fathers of modern neurosurgery: Fasiani, Frugoni, Visalli, Morello, Castellano, Chiasserini, Patricolo, and Guidetti.

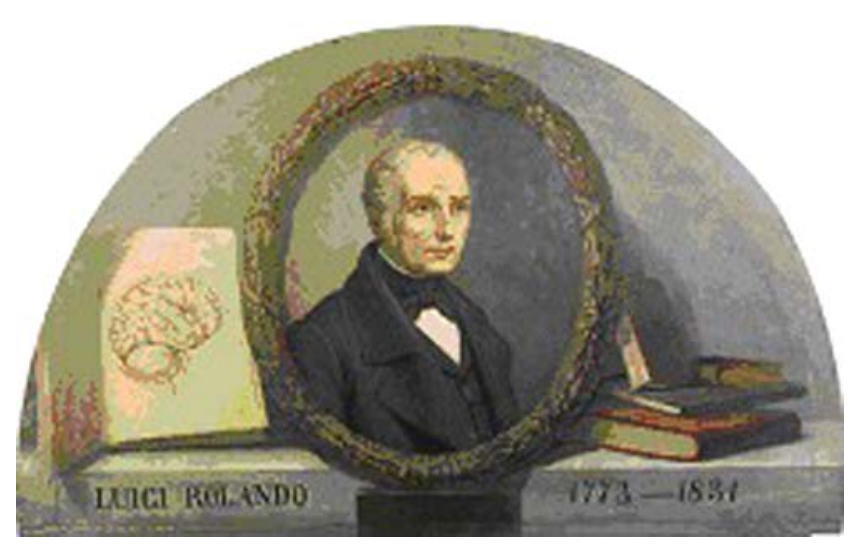

Fig. 3 Pasquale Baroni: artistic paint of Luigi Rolando, Institute of Human Anatomy "Luigi Rolando", Turin 
Table 1 Most relevant operations for intracranial and spinal pathologies in the last two decades of nineteenth century [5]

\begin{tabular}{|c|c|c|}
\hline Surgeon & Pathology & City \\
\hline Palasciano & Removal of hydatid cyst of the vertex & Naples \\
\hline Novaro & Parasaggittal frontal hyperostosing meningioma in patients with seizures and external irregularities of bone & Turin \\
\hline Durante & "Fibroma" of the base of the skull with extension into the nasal fossae, with transpalatine approach & Rome \\
\hline Caponotto, Pescarolo & Surgery for tumors of the spine & Turin \\
\hline Bendandi & Surgery for tumors of the cerebellopontine angle & Bologna \\
\hline Gioppi & Surgery for carotid-cavernous fistula & Padua \\
\hline Vanzetti & Surgery for intracranial aneurysms & Verona \\
\hline Caponotto, Novaro & Surgery for trigeminal neuralgia (gasserectomy from the forame ovale) & Turin \\
\hline D’Antona & & Naples \\
\hline D’Antona & Surgery for epilepsy & Naples \\
\hline
\end{tabular}

\section{Contemporary neurosurgery in Italy}

Therefore, in Italy as in other countries, neurosurgery developed out of general surgery. In particular, the most important schools of surgery of Florence, Bologna, Pisa, Turin, and Padua-Venice and later of Pavia, Verona, Milan, Rome, and Naples handed down science and art from generation to generation till now. The final establishment of modern Italian neurosurgery has been linked to the development of clinical neurology, neuropathology, neurophysiology, and neuroanesthesiology occurred during the second half of nineteenth and the first half of twentieth centuries. The last contribute has been brought by neuroradiology, especially during the last 30 years.

The Italian Society of Neurosurgery (SINch) was founded on May 29, 1948. Its aim is to get together the Italian neurosurgeons, to defend and to protect their prestige and interests, to promote the progresses of the specialty, to make easier the relations between Italian and foreign neurosurgeons, and to get in touch with other Italian, foreign, and international scientific associations. The official journal of the SINch is the Journal of Neurosurgical Sciences (Minerva Medica) and the official website is www.sinch.it. The fundamental articles of the statute of SINch are 16 (Table 2) and were approved on February 18, 1962. The SINch has ten active study groups: (1) neurotraumatology, (2) spine surgery, (3) surgery of peripheral nervous system, (4) functional and stereotactic neurosurgery, (5) pediatric neurosurgery, (6) neurooncology, (7) neuroendoscopy, (8) radiosurgery, (9) hemodynamics, and (10) history of neurosurgery. Through the scientific cooperation among various national centers and by the activity of the study groups identified by the Directory Board of the SINch, several guidelines for the diagnosis and treatment of various neurosurgical pathologies have been elaborated. In addition, the SINch concurs with the European Association of Neurosurgical Societies directives regarding the implementation of uniformly high standards of neurosurgical care throughout Europe and at national level.

The scientific activity of Italian neurosurgical community consists of (1) an increasing number of published articles in international neurosurgical journals, (2) active participation to international prestigious meetings, courses, and conferences, with outstanding lectures, and (3) organization of almost two local, national, or international meetings each month in Italian cities. On considering the articles indexed in the PubMed website, starting from the year 1970, more than 3,700 neurosurgical articles have been published by Italian authors; in particular, 1,600 papers have been published from 1970 to 2000 and about 2,070 during the last 10 years.

In Italy, we have about 150 units of neurosurgery (including units of neurotraumatology, spine surgery, and pediatric neurosurgery); each unit serves a mean of about 400,000 inhabitants and performs a mean of 600 operations a year (ranging from 300 to $>2,000$ ), with a case-mix of $50-70 \%$ spine and peripheral nerve surgery versus $30-50 \%$ of brain surgery. As regarding technology, starting from June 2004, the Department of Neurosurgery of Sant'Andrea Hospital is active in the so called "BrainSUITE" (BrainLAB AG, Feldkirchen, Germany; Fig. 4), the first installed in Italy and Europe: It is a high-technology operative room with $1.5 \mathrm{~T}$ magnetic resonance imaging, neuronavigational system, and microscope fully integrated.

The Italian neurosurgeons are about 1,500: On considering an overall population of more than 55 millions of inhabitants (data of 2002), we have a neurosurgeon every 37,000 citizens. This proportion represents an adequate coverage for general population. On the whole, people are enough satisfied with the medical delivery system, including neurosurgery, especially in north and middle side of the country. It must be underlined that for "minor" surgical (including neurosurgical) procedures, there are in almost all hospitals of the country long or very long waiting lists (up to more than 6 months). 
Table 2 Most relevant articles of the statute of SINch

1. Founder members: G.M. Fasiani (also one of the founder of WFNS), A. Chiasserini Sr., P.E. Maspes, M. Milletti, E. Miserocchi, G. Morello, M. Quarti Trevano, U. Sacchi, F. Visalli

2. Aims: No-profit association

3. Members are divided into (a) founders, (b) honorary, (c) active, (d) adherent, and (e) international

4. Organisms of the SINch are (a) General Assembly of Members and (b) Directory Board

5. The Assembly can be ordinary or extraordinary and all members can attend it. Ordinary assembly: (a) at least once a year, (b) admission of new members, (c) economical resume, and (d) special mansions to the Directory Board

6. The SINch is administered by the Directory Board, elected by the active members and composed by President ( 2 years), Vice-President ( 2 years), Past-President (2 years), Secretary (maximum 6 years), Treasurer (maximum 6 years), and nine Councilors (re-electable, maximum 4 years)

7. The President represents the Society and acts as chairman of the Assembly. If he cannot, the Vice-President will substitute him

8. The Secretary keeps relations between the Directory Board and the members and with foreign and international scientific associations

9. The Directory Board organizes the scientific activity of SINch in study groups and draws every year a report about the activity of the Society and of the initiatives for the future

10. Members meet at least every year in the annual meeting

As far as patients in Italy are concerned, we have both government-sponsored care and private insurance, with a medium rate of $80 \%$ versus $20 \%$, with sharp differences among north, middle, and south side of the country (a small amount of people of south has private insurance). Nevertheless, lower socioeconomic people are completely covered by government-sponsored care. As far as practicing neurosurgeons is concerned, malpractice litigation is an increasing major problem, both for some avoidable medical errors, for not always clear information given to patients, and for the even higher results expectancy of patients and their relatives.

\section{Educational programs}

In Italy, we have 25 schools of neurosurgery (one school every about two millions of people), consisting of a 5-year

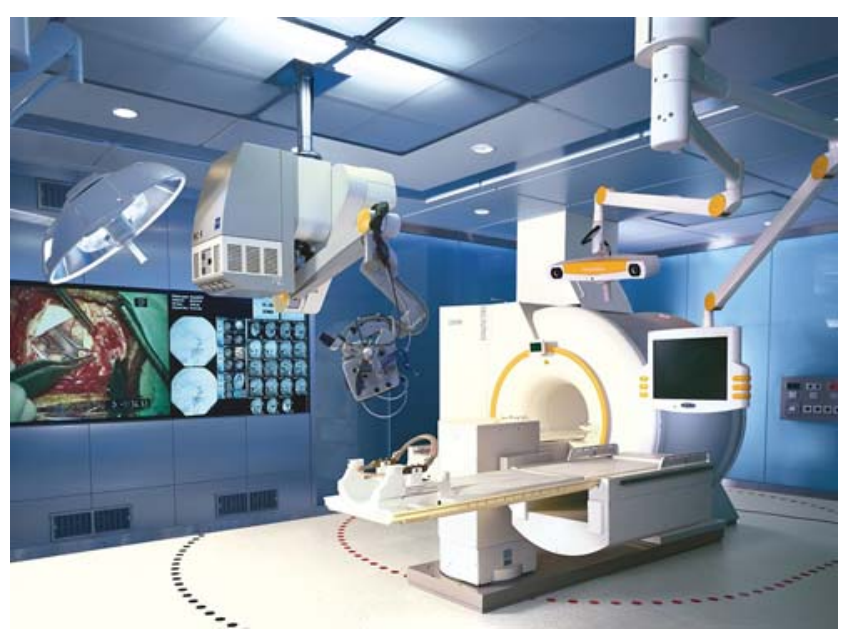

Fig. 4 The high-technology operative room "BrainSUITE" (BrainLAB) installed in 2004 in the Sant'Andrea Hospital of Rome neurosurgical training program after the 6-year Medicine and Surgery degree. Each school admits one to four new residents each year and at the end of their residency program, each of them should have performed about 500 surgical procedures.

The problem of practical training in cadaver laboratories has not been completely solved yet. In fact, despite the significant Italian tradition of important anatomical studies $[5,6]$, an outdated law, historically influenced by the Catholic Church, restricts the use of cadavers for teaching and scientific purposes. Considering the new common European Constitution, it seems advisable that a political solution could arrive from the European Community, in order to improve the quality of training in the disciplines with high social impact such as neurosurgery.

Anyway, at the end of 2005, in coincidence with the Annual Meeting of SINch in Turin, the Minister of Health declared to be possible to have dissection courses on cadaver heads regularly imported from other countries during well-established educational events. The National Meeting of Turin was the first in the history of SINch preceded and followed by dissection courses on injected cadaver heads and temporal bone specimens. That Minister's declaration opened a season of many dissection courses: During the last 2 years and a half, we organized more than ten dissection courses in several locations (Turin, Rome, L'Aquila, Naples, Como). At the moment, it seems very difficult to organize dissection courses on cadavers for spine surgery.

Hoping that in a near future the juridical regulations on the use of cadavers for educational purposes will change, we continue to work hardly in this direction. Notwithstanding some difficulties in training and in job finding, in our country, the neurosurgery residency programs seem to attract several very good medical students every year. 


\section{Conclusions}

With the aim of raising the standards of care of patients and of training of young neurosurgeons, the SINch submitted the following recommendations to the Italian authorities:

1. Limitation of the number of neurosurgical centers on the national territory

2. Implementation of existing centers, with an adequate number of beds for intensive care unit (ICU; 20\%) and creation of independent neuroradiology and neuroanesthesia services

3. Neurosurgical subspecialties services should be encouraged and set up at the large centers on a departmental basis

4. Limit the creation of new residency schools, upgrading the existing ones to European standards and seeking to reduce the number of trainees

5. Ensure the presence of a consulting neurosurgeon for all local health service clinics

6. Arrangement for the reorganization of nursing personnel, setting up university courses of diploma for operating room nurses, neurosurgical nursing, and ICU nursing

\section{References}

1. Capasso L, Michetti E, Pierfelice L, D'Anastasio R (2002) Neurosurgery 7000 years ago in central Italy. Lancet 359:2206

2. De Caro GM, Brunori A, Giuffrè R (1998) Neurosurgery in Rome: 1880-1970. Ann Ital Chir 69:249-284

3. de Divitiis E, Cappabianca P, de Divitiis O (2004) The "Schola Medica Salernitana": the forerunner of the modern university medical schools. Neurosurgery 55:722-745

4. Durante F (1887) Contribution to endocranial surgery. Lancet 2:654-655

5. Giuffrè R (1984) Successful radical removal of an intracranial meningioma in 1835 by Professor Pecchioli of Siena. J Neurosurg $60: 47-51$

6. Guidetti B, Giuffrè R, Valente V (1983) Italian contribution to the origin of neurosurgery. Surg Neurol 20:335-346

7. Guidetti B (1983) Francesco Durante. Surg Neurol 20:1-3

8. Tomasello F, Germanó A (1996) Francesco Durante: the history of intracranial meningiomas and beyond. Neurosurgery 59:389-396

\section{Comments}

Enrico de Divitiis, Naples, Italy

The authors have written a very comprehensive and extremely interesting account of the Italian Society of Neurosurgery. The present article traces its development from the early success in the treatment of some intracranial lesions at the end of the nineteenth century, up to the present modern state of the neurosurgery in Italy. Then, it provides a carefully documented overview and describes the foundation and development of Italian neurosurgical units which have particularly accounted for the clinical and scientific training of young residents. Reading this article, one is made aware of the many contributions by the faculty of this Society in the use of the most modern technological resources for a modern neurosurgery. Although the article lacks in future perspectives related to the problem of the organization of standardized neurosurgical training in European Union, it certainly thrives in excellent detail about this institution and many of its contributions. Finally, the authors provided a fascinating account how an institution often seems to develop at the instigation of some farseeing individuals that have played by innovative and progressive contributions a vital role in providing the nucleus for one of the most prominent neurosurgical societies in Europe. Neurosurgical Review has to be congratulated on publishing this kind of contributions; the advancements of scientific knowledge are often provided by the study of past experiences. The eulogy of previous great individuals should be not only as a memory but also as a way by which to recognize the heritage they have given to the following generations.

\section{Massimo Collice, Milan, Italy}

The article is a summary of major Italian contributions to the development of neurosurgery. I would like to specify that Giulio Casserio lived in the 1600 years while he is mentioned in the paragraph concerning the eighteenth century. Also, the sentence "As far as patients, in Italy we have both government sponsored-care and private insurance with a medium rate of $80 \%$ versus $20 \%$ " is misleading. All Italian citizens have public health insurance which guarantees all treatments to the entire population (not only to the lower socioeconomic classes). Citizens can be admitted to and treated by all hospitals in the country. Private insurances are usually subscribed to choose a specific doctor/equipes or to have more comforts (private room), or to be treated in shorter time. However, it must be said that for important diseases, there are virtually no waiting time to be treated.

\section{Alessandro Ducati, Turin, Italy}

Any time the history of neurosurgery is approached, the authors have to deal with the Italian Medieval and Renaissance history of medicine. The relevance of the Italian contribution is mainly due to the anatomical studies carried out in Padua, in Bologna, and in Naples that prompted the scientists to overcome the limits of the traditional and ritual Greco-Roman medicine and to approach the problems with a fact based attitude. This standard, namely to describe the anatomy correctly in order to know the normal aspects and distinguish the disease, has been set in those centuries and still holds true: It is the only way to start the plan for a proper therapy. After that glorious period, the quality of the Italian medicine and its name in the world blurred a little, due to political and sociological reasons. But now, we are going back again to basic studies, in order to recapture our place in the scientific community.

This is a nice review of history and recent development of Italian neurosurgery. Most of the facts summarized here are known since years, but as sparse information or old reports. Therefore, I appreciated this easy, complete, and flowing illustration of development of neurosurgery in Italy, together with a fair and honest vision of its actual state. I think that European colleagues will enjoy it as well. 